\title{
Leptin, hs-CRP and HOMA-IR in patients with type 2 diabetes: The role of different levels of vitamin $D$ deficiency
}

\author{
Salome Sadat Salehi, Soghra Rabizadeh, Sahar Karimpour Reyhan, Marjan_Mouodi, \\ Manouchehr Nakhjavani, Alireza Esteghamati, Hossein Mirmiranpour*
}

Endocrinology and Metabolism Research Center, Vali-Asr Hospital, Imam Khomeini Hospital Complex, Tehran University of Medical Sciences, Tehran, Iran

*Corresponding author: Hossein Mirmiranpour, MD, PhD, Assistant Professor of Biochemistry, Endocrinology and Metabolism Research Center (EMRC), Vali-Asr Hospital, School of Medicine, Tehran University of Medical Sciences, Tehran, Iran.

Submission Date: September $26^{\text {th }}, 2019$. Acceptance Date: November $28^{\text {th }}, 2019$. Publication Date: November 30 ${ }^{\text {th }}, 2019$

Citation: Salehi S.S., Rabizadeh S., Reyhan S.K., Mouodi M., Nakhjavani M., Esteghamati A., Mirmiranpour $\mathrm{H}^{*}$. Leptin, hs-CRP and HOMA-IR in patients with type 2 diabetes: The role of different levels of vitamin D deficiency. Functional Foods in Health and Disease 2019; 9(11): 695-705. DOI: https://doi.org/10.31989/ffhd.v9i11.661

\section{ABSTRACT}

Background: To evaluate the effects of different levels of vitamin D deficiency on blood glucose, leptin, high sensitivity C-reactive protein (hs-CRP), and insulin resistance and their associations.

Methods: We quantified serum vitamin D level, hs-CRP, leptin, and fasting blood sugar (FBS) levels in 25 type- 2 diabetic patients with deficient serum levels of 25 -hydroxy vitamin $\mathrm{D}(\leq 15$ $\mathrm{ng} / \mathrm{ml}$ ) and 25 type-2 diabetic patients with insufficient serum levels of 25 -hydroxy vitamin D (16 to $30 \mathrm{ng} / \mathrm{ml}$ ). The two groups were matched according to age, sex, and body mass index (BMI). Homeostasis model assessment of insulin resistance (HOMA-IR) was calculated by a formula based upon values of FBS and insulin concentrations.

Results: The mean value of vitamin D levels was $7.67 \pm 3.10$ in the vitamin D deficient group and 23.20 \pm 9.97 in the vitamin D insufficient group. Patients with vitamin D deficiency had significantly higher FBS, postprandial glucose (PPG) and hemoglobin A1C (HbA1C) as compared to vitamin D insufficient group $(\mathrm{p}<0.01)$. We studied correlations of hs-CRP, HOMA$\mathrm{IR}$, and leptin in both vitamin D insufficient and deficient groups. There were significant positive correlations between leptin with hs-CRP $(r=0.58, p<0.01)$ and with HOMA-IR $(r=0.49$, $p<0.05)$ in vitamin $\mathrm{D}$ deficient group. These correlations remained significant after multiple adjustment for age, sex, BMI, systolic and diastolic blood pressure.

Conclusion: In conclusion, vitamin D deficient diabetic patients had elevated FBS, PPG and HbA1C compared with insufficient ones. The results also could possibly point the effect of vitamin D deficiency level on leptin associations with hs-CRP and insulin resistance.

Keywords: Vitamin D deficiency, type 2 diabetes, leptin, $\mathrm{C}$ reactive protein, homeostasis model assessment of insulin resistance 


\section{INTRODUCTION}

Vitamin D deficiency is an increasing public health concern ${ }^{1}$. In type 2 diabetes, the prevalence of vitamin D deficiency is $20 \%$ higher than in non-diabetics ${ }^{2}$. Low vitamin D status can be caused by a number of factors, including insufficient cutaneous synthesis (due to limited sunlight exposure or aging), inadequate intake and absorption of vitamin D, or obesity ${ }^{3}$. High global prevalence and disease burden of vitamin D deficiency has led to the introduction of a roadmap for action in low and middle income countries ${ }^{4}$. Data from studies suggest that widespread vitamin D deficiency persists regardless of human development index of the country and fortification policies ${ }^{5}$.Vitamin D is not only important in mineral homeostasis but it is also an anti-inflammatory hormone that can regulate immune responses, cell proliferation, and endothelial function ${ }^{6,7}$. Vitamin D deficiency is playing an important role in the genesis of coronary risk factors and cardiovascular disease, and seems to predispose to hypertension, diabetes and the metabolic syndrome ${ }^{8,9}$. Vitamin $\mathrm{D}$ is thought to have both direct (by the activation of the vitamin $\mathrm{D}$ receptor) and indirect (by the regulation of calcium homeostasis) effects on various mechanisms related to the pathophysiology of type 2 diabetes ${ }^{10}$. The effect of vitamin $\mathrm{D}$ on pancreatic cells and subsequent insulin release is mediated through vitamin $\mathrm{D}$ receptors ${ }^{11}$. Although the mechanisms are not fully understood, vitamin D deficiency impairs insulin secretion of pancreatic cells and increases insulin resistance, which are major factors in the pathogenesis of type 2 diabetes ${ }^{12,13}$. Animal and in vitro studies provide evidence that vitamin $\mathrm{D}$ indirectly impacts diabetes through insulin resistance ${ }^{14}$. The simplest and most commonly used surrogate estimate of insulin resistance is the homeostasis model assessment of insulin resistance (HOMA-IR). HOMA-IR is calculated by a formula based upon values of fasting blood sugar (FBS) and insulin concentrations ${ }^{15}$.

Leptin is an adipocyte-secreted hormone that has been proposed to regulate energy homeostasis as well as metabolic, neuroendocrine, and immune functions. Leptin may also directly regulate glucose homeostasis independently of its effects on adiposity. Leptin affects glycemia at least in part via the central nervous system, but it may also directly regulate the physiology of pancreatic $\beta$-cells and peripheral insulin-sensitive tissues ${ }^{16}$. Vitamin D present a direct inhibitory effect on leptin secretion from human adipose tissue culture ${ }^{17}$.

Active vitamin $\mathrm{D}$ also diminishes the expression of proinflammatory cytokines which can induce production of C-reactive protein (CRP) ${ }^{18}$. Clinical data underlie the importance of both CRP and leptin in estimating CVD risk especially in clinical states where chronically elevated CRP levels and leptin resistance coexist ${ }^{19}$.

Here we aimed to study the effects of different levels of vitamin D hypovitaminosis on blood glucose, insulin resistance, leptin and high-sensitivity CRP (hs-CRP) and their associations.

\section{MATERIALS AND METHODS}

This is a descriptive cross-sectional study on 50 patients with type 2 diabetes referring to the diabetes clinic of Vali-asr Hospital, affiliated with Tehran University of medical science. The diagnosis of diabetes was made based on American Diabetes Association $2015^{20}$. Exclusion criteria were smoking, pregnancy, proteinuria, renal involvement (creatinine $>1.5 \mathrm{mg} / \mathrm{dl}$ or GFR $<70 \mathrm{cc} / \mathrm{min}$ ), glomerulonephritis, congestive heart failure, insulin therapy, and hospital admission in recent months. None of the participants had any overt diabetic complication. Findings from studies in Iran have demonstrated that vitamin D deficiency is a highly prevalent problem among Iranians ${ }^{21,22}$. Even though, no optimal level of 25-hydroxy vitamin D $[25(\mathrm{OH}) \mathrm{D}]$ has been agreed upon, Most agree that A circulating level of 25-OH-D 
concentrations $>30 \mathrm{ng} / \mathrm{mL}$ are considered to be sufficient and is required to maximize vitamin D's beneficial effects for health ${ }^{23}$. According to the baseline values, all of diabetic patients in our study were vitamin D deficient or insufficient and none of the patients had sufficient levels ( >30 $\mathrm{ng} / \mathrm{ml}$ ) of serum $25(\mathrm{OH}) \mathrm{D}$. A total of 25 type-2 diabetic patients with very low serum levels of 25-OH-D ( $\leq 15 \mathrm{ng} / \mathrm{ml}$; deficient) and 25 type-2 diabetic patients with low serum levels of 25 OH-D (16 to $30 \mathrm{ng} / \mathrm{ml}$; insufficient) were recruited ${ }^{9}$. We defined vitamin $\mathrm{D}$ deficiency and insufficiency according to the ranges proposed by the recently published K/DOQI guidelines. Thus, vitamin D stores are considered adequate when $25(\mathrm{OH}) \mathrm{D}$ levels are above $30 \mathrm{ng} / \mathrm{ml}$. Levels between 16 and $30 \mathrm{ng} / \mathrm{ml}$ represent vitamin D insufficiency. Vitamin D deficiency is defined as $25(\mathrm{OH}) \mathrm{D}$ levels less or equal to $15 \mathrm{ng} / \mathrm{ml}^{24,25}$. Two groups were matched according to age, sex, and body mass index (BMI). Diabetes mellitus was diagnosed according to the criteria of the American Diabetes Association ${ }^{26}$. Use of vitamin D supplements, drugs with known effect on serum concentrations of vitamin D, smoking, pregnancy, creatinine $>1.5 \mathrm{mg} / \mathrm{dl}$ or GFR $<70$ cc/min, glomerulonephritis, congestive heart failure, use of antioxidant, statins, hormone replacement therapy and hospital admission in previous 6 months, history of rheumatologic, gastrointestinal, and liver dysfunctions were defined as exclusion criteria. Demographic and anthropometric data including age, sex, duration of diabetes, height, weight in light clothing, and blood pressure in sitting position were recorded.

Blood pressure was re-measured twice after $5 \mathrm{~min}$ and averaged. The BMI $(\mathrm{kg} / \mathrm{m} 2)$ was calculated according to the Quetelet formula. HOMA-IR was calculated according to; fasting insulin $(\mathrm{U} / \mathrm{mL}) \times$ FBS $\left(\mathrm{mg} / \mathrm{ld}\right.$.) $/ 405^{27}$. The research was carried out according to the principles of the Declaration of Helsinki. The local ethics review committee of Tehran University of Medical Sciences approved the study protocol. All the patients received and signed written informed consent.

\section{Blood samples}

Blood samples were collected after 12 hours of fasting. They were centrifuged and kept at $-70 \circ \mathrm{C}$ until analysis. Serum creatinine, FBS, total cholesterol, triglycerides, high-density lipoprotein cholesterol (HDL-C), low density lipoprotein-cholesterol (LDL-C), and HbA1c were measured for all participants. Glucose measurements (intra-assay coefficient of variants [CV] 2.1\%, intraassay CV 2.6\%) were carried out using the glucose oxidase method. Insulin was measured (intraassay CV $4.7 \%$, inter-assay CV 3.3\%) by immune radiometric method (Immunotech, Finland). Cholesterol, HDL-C, LDL-C and triglycerides were determined using direct enzymatic methods (Parsazmun , Karaj, Iran). Serum leptin concentration was determined using an enzyme-linked immunosorbent assay (DRG Instruments $\mathrm{GmbH}$, Germany), with an intra-assay coefficient of variation of 5.9-6.9\% and an inter-assay coefficient of variation of 8.6-11.5\%. Hs-CRP was assessed using a two-site, enzyme-linked immunosorbent assay (ELISA) (Diagnostic Biochem, London, Ontario, Canada). Sensitivity of the assay was $10 \mathrm{ng} / \mathrm{L}$. Intra- and inter-assay coefficients of variation $(\mathrm{CV})$ were $8 \%$ and $10 \%$ respectively. Serum $25(\mathrm{OH})$ Vitamin D was determined using enzyme-linked immunosorbent assay technique (DIAsource, Louvain-laNeuve, KAP1971, Belgium) Intra- and inter-assay coefficients of variation (CV) were $7.8 \%$ and $7.4 \%$ respectively. Limit of detection was $2.81 \mathrm{ng} / \mathrm{ml}$.

\section{Statistical analysis}

Data are analyzed using SPSS software (version16.0; SPSS, Chicago, Illinois, USA). SmirnovKolomogrov test was employed to test the normality of the variables in each group. The continuous variables are expressed as means \pm standard deviation (SD). Quantitative variables 
were compared between the two groups using t-test and Mann-Whitney test, while qualitative variables were compared with chi-square test. The magnitude of the relationship between continuous variables (leptin, hs-CRP and HOMA-IR) was measured using the Pearson correlation coefficient for linear relationships. Partial correlation coefficient after multiple adjustments for age, gender, BMI and systolic blood pressure (SBP) and diastolic blood pressure $(\mathrm{DBP})$ were also calculated. $\mathrm{P}$ values $<0.05$ were considered statistically significant.

\section{RESULTS}

Demographic and biochemical characteristics of the participants are illustrated in table1. There was no significant difference between groups with respect to age, sex, duration of diabetes, BMI, systolic and diastolic blood pressure, cholesterol, LDL-C, HDL-C, triglycerides and also medications (antidiabetic agents and hypertensive drugs).

\section{Table 1: Baseline Characteristics of study population}

\begin{tabular}{|c|c|c|c|}
\hline & $\begin{array}{c}\text { Vitamin D Deficient } \\
\qquad(\leq 15 \mathrm{ng} / \mathrm{ml})\end{array}$ & $\begin{array}{l}\text { Vitamin D Insufficient } \\
(16-30 \mathrm{ng} / \mathrm{ml})\end{array}$ & P-value \\
\hline Number & 25 & 25 & \\
\hline Gender (male, female) & $(13,12)$ & $(7,18)$ & NS \\
\hline Age(years) & $56.56 \pm 11.79$ & $55.60 \pm 14.20$ & NS \\
\hline BMI $\left(\mathrm{kg} / \mathrm{m}^{2}\right)$ & $28.32 \pm 4.47$ & $27.54 \pm 3.37$ & NS \\
\hline Waist circumference $(\mathrm{cm})$ & $94.08 \pm 10.76$ & $93.84 \pm 9.33$ & NS \\
\hline Duration of diabetes (year) & $9.42 \pm 6.4$ & $9.65 \pm 5.31$ & NS \\
\hline \multicolumn{4}{|l|}{ Blood pressure (mmHg) } \\
\hline SBP & $127.76 \pm 21.94$ & $132.16 \pm 20.14$ & NS \\
\hline DBP & $79.92 \pm 11.63$ & $76.12 \pm 12.80$ & NS \\
\hline MAP & $95.86 \pm 14.20$ & $94.80 \pm 9.33$ & NS \\
\hline \multicolumn{4}{|l|}{ Plasma glucose $(\mathrm{mg} / \mathrm{dl})$} \\
\hline FBS & $199.61 \pm 54.74$ & $146.78 \pm 46.4$ & $<0.01$ \\
\hline PPG & $284.1 \pm 68.4$ & $199.83 \pm 40.74$ & $<0.01$ \\
\hline $\operatorname{HbA1C}(\%)$ & $8.37 \pm 1.81$ & $6.93 \pm 1.33$ & $<0.01$ \\
\hline $\operatorname{Insulin}(\mu \mathrm{u} / \mathrm{ml})$ & $22.38 \pm 15.21$ & $18.19 \pm 12.06$ & NS \\
\hline HOMA-IR & $9.16 \pm 5.83$ & $7.16 \pm 5.47$ & NS \\
\hline Hs-CRP( mg/ml) & $4.23 \pm 0.43$ & $3.09 \pm 0.24$ & NS \\
\hline Creatinine $(\mathrm{mg} / \mathrm{dl})$ & $0.96 \pm 0.22$ & $0.99 \pm 0.27$ & NS \\
\hline Urea(g/24h) & $27.13 \pm 13.53$ & $30.3 \pm 16.72$ & NS \\
\hline Uric Acid(mg/dl) & $5.27 \pm 1.07$ & $5.23 \pm 1.25$ & NS \\
\hline \multicolumn{4}{|l|}{ Plasma cholesterol (mg/dl) } \\
\hline Total & $187.38 \pm 29.72$ & $190.78 \pm 52.72$ & NS \\
\hline LDL & $106.05 \pm 27.96$ & $108.91 \pm 42.95$ & NS \\
\hline HDL & $43.75 \pm 9.71$ & $44.13 \pm 10.86$ & NS \\
\hline Plasma triglyceride $(\mathrm{mg} / \mathrm{dl})$ & $194.67 \pm 86.82$ & $155.95 \pm 70.51$ & NS \\
\hline Vitamin $\mathrm{D}(\mathrm{ng} / \mathrm{dl})$ & $7.67 \pm 3.10$ & $21.94 \pm 5.98$ & $<0.001$ \\
\hline Leptin (ng/mL) & $79.92 \pm 11.63$ & $76.12 \pm 12.80$ & NS \\
\hline \multicolumn{4}{|l|}{ Medication (\%) } \\
\hline OAD & 80 & 76 & NS \\
\hline Insulin & 15 & 16 & \\
\hline OAD + Insulin & 8 & 4 & \\
\hline Antihypertensive drugs & 32 & 34 & NS \\
\hline
\end{tabular}

Abbreviations: BMI, body mass index; SBP, systolic blood pressure; DBP, diastolic blood pressure; MAP, mean arterial pressure; FBS, fasting blood sugar; PPG, postprandial glucose; HbA1C, hemoglobin A1C; HOMA-IR, homeostasis model assessment- Insulin resistance; hs-CRP, high-sensitivity C-reactive protein; LDL, low density lipoprotein; TG, Triglyceride; HDL; high density lipoprotein; OAD: Oral antidiabetic drug. 
The mean value of vitamin D levels was $7.67 \pm 3.10$ in the vitamin $\mathrm{D}$ deficient group and 23.20 \pm 9.97 in the vitamin D insufficient group. FBS, PPG and HbA1C levels were significantly higher in vitamin $\mathrm{D}$ deficient patients $(\mathrm{P}<0.01)$, whereas other covariates did not show any significant difference (Table 1). We studied correlations of leptin with hs-CRP and HOMA-IR in both vitamin D insufficient and deficient groups (Figure 1 and 2). There were only significant positive correlations between leptin with hs-CRP $(r=0.58, p$ value $<0.01)$ and with HOMA-IR $(r=0.49, p$ value $<0.05)$ in vitamin $\mathrm{D}$ deficient group; These correlations remained significant after multiple adjustment for age, sex, BMI, systolic blood pressure (SBP) and diastolic blood pressure (DBP) (Table 2).
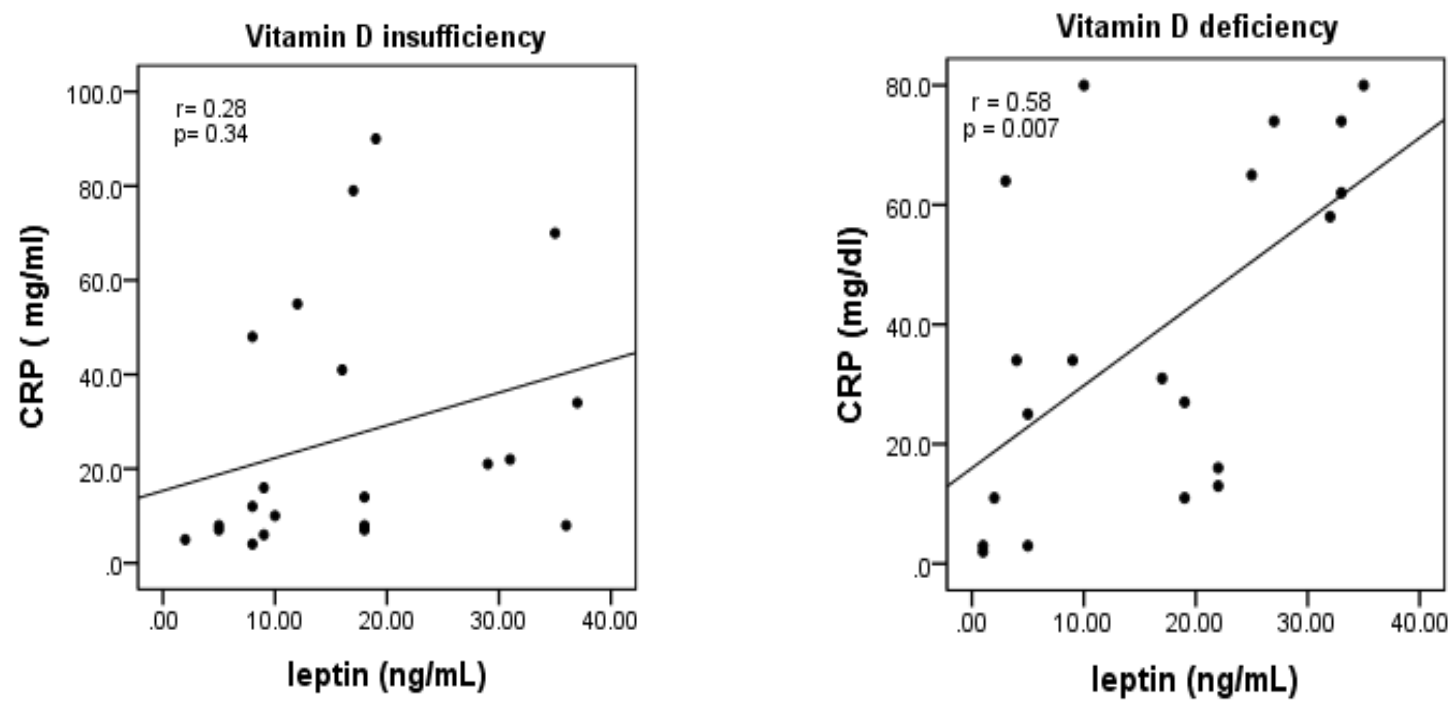

Fig 1: Scatter plot demonstrating the correlation between leptin and hs-CRP in vitamin D insufficient (16 to $30 \mathrm{ng} / \mathrm{ml}$ ) and vitamin D deficient ( $\leq 15 \mathrm{ng} / \mathrm{ml})$ type 2 diabetic patients.
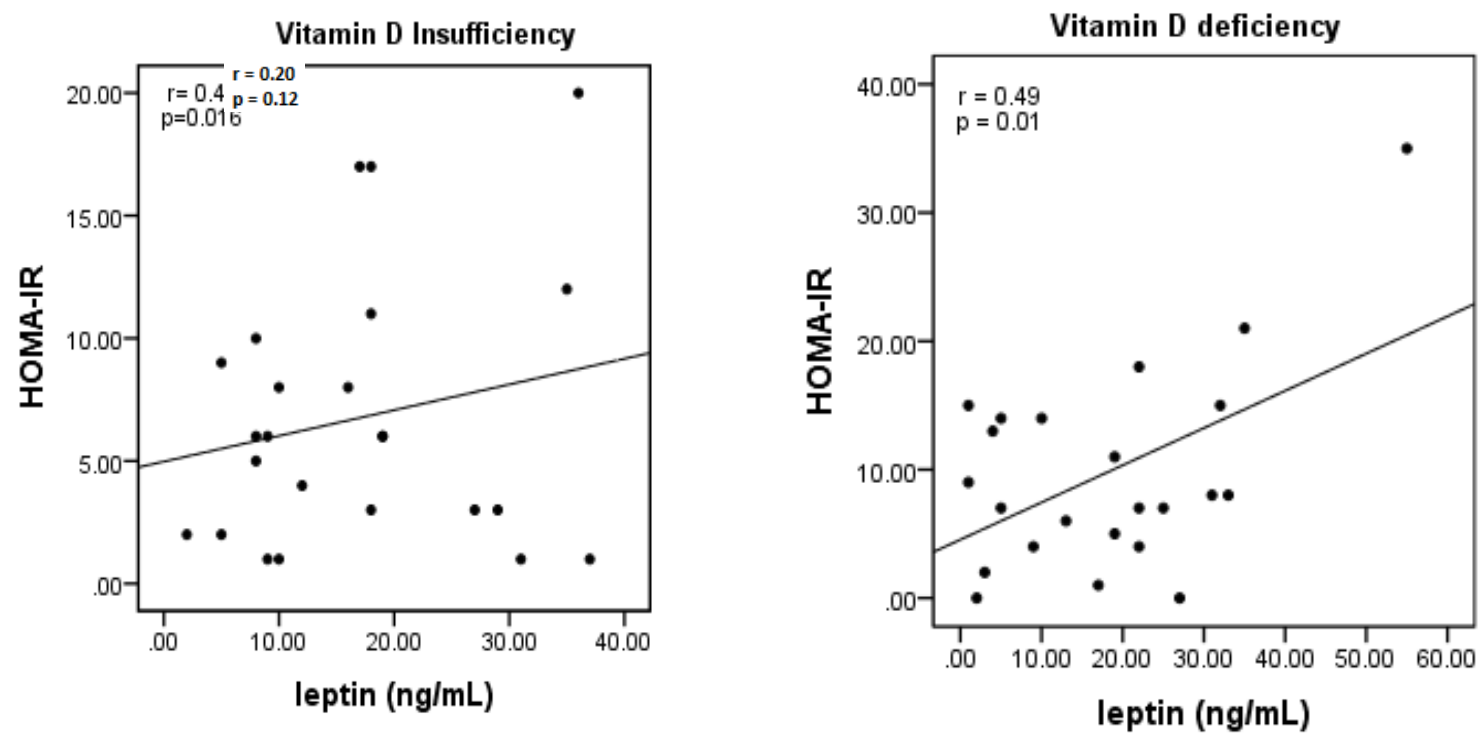

Fig 2: Scatter plot demonstrating the correlation between leptin and HOMA-IR in vitamin D insufficient (16 to $30 \mathrm{ng} / \mathrm{ml})$ and vitamin D deficient $(\leq 15 \mathrm{ng} / \mathrm{ml})$ type 2 diabetic patients. 
Table 2: Correlation coefficient (r) between leptin with hs-CRP and HOMA-IR in vitamin D deficient and insufficient type 2 diabetic patients before and after adjustment for age, sex, BMI, systolic blood pressure (SBP) and diastolic blood pressure (DBP).

\begin{tabular}{lllllll}
\hline Leptin correlation & with & $\begin{array}{c}\text { Without } \\
\text { adjustment }\end{array}$ & Adjusted for & & \\
& & & Age and sex & BMI & SBP and DBP & $\begin{array}{l}\text { Age, sex, BMI, } \\
\text { SBP, DBP }\end{array}$ \\
Vitamin D Deficient & Hs-CRP & $0.58^{* *}$ & $0.57^{*}$ & $0.57^{* *}$ & $0.61^{* *}$ & $0.59^{*}$ \\
$(\leq 15 \mathrm{ng} / \mathrm{ml})$ & HOMA & $0.49^{*}$ & $0.58^{* *}$ & $0.49^{*}$ & $0.52^{*}$ & $0.59^{* *}$ \\
& Hs-CRP & 0.28 & $0.45^{*}$ & 0.09 & 0.38 & 0.40 \\
$\begin{array}{l}\text { Vitamin D Insufficient } \\
(16-30 \mathrm{ng} / \mathrm{ml})\end{array}$ & HOMA & 0.20 & 0.20 & 0.19 & 0.30 & 0.32
\end{tabular}

$* \mathrm{P}<0.05 \quad * * \mathrm{P}<0.01$

Abbreviations: BMI, body mass index; SBP, systolic blood pressure; DBP, diastolic blood pressure; hs-CRP, highsensitivity C-reactive protein; HOMA-IR, homeostasis model assessment- Insulin resistance.

\section{DISCUSSION}

Vitamin D deficiency, as a vital problem in the new civilization, has attracted several investigations in the medicine. In a systemic review, the prevalence of vitamin D insufficiency in Iranian children and adolescents was $31 \%$ (CI 95\% 30-31) ${ }^{28}$. The present study demonstrated that serum FBS, PPG and HbA1C are higher in vitamin D deficiency in type 2 diabetic patients. Our results are generally consistent with previous reports ${ }^{3,29}$. It has been shown that deficiency in serum $25(\mathrm{OH}) \mathrm{D}$ levels decrease insulin secretion and increase peripheral insulin resistance and blood glucose $\mathrm{e}^{30}$. With regard to glucose homeostasis, vitamin D affects pancreatic beta-cell proliferation and survival and its ability to respond to situations of increased insulin demand such as in type 2 diabetes. ${ }^{3}$. Vitamin D deficiency may cause disturbances in the vitamin D signaling pathway. In vivo study showed impaired insulin secretion in vitamin D-deficient rats and clearly established a molecular role of the Vitamin D receptor in the endocrine function of the pancreas $^{31}$.

We compared the correlations among leptin, CRP and HOMA-IR in vitamin D deficient and insufficient diabetic patients and we showed a significant positive association between leptin with CRP and HOMA-IR in vitamin D deficient group. These correlations remain significant after multiple adjustments for age, sex, BMI, systolic blood pressure and diastolic blood pressure. Similarly several studies have demonstrated a significant positive correlation between insulin resistance and leptin, independently of body weight or adiposity, in both normoglycemia and diabetes ${ }^{32,33}$. A population-based study by Zimmet et al. suggested that insulin resistance or concentration may contribute to the relatively wide variation in leptin levels or alternatively, leptin may play a role in the etiology of insulin resistance ${ }^{34}$. As stated earlier, vitamin D deficiency increases insulin resistance which has been found to induce leptin production ${ }^{35}$. Mechanism of both direct and centrally-mediated leptin action on the $\beta$-cell has been proposed to occur through sympathetic inhibition of $\beta$-cell (glucose stimulated) insulin secretion and improving peripheral insulin sensitivity ${ }^{36-38}$ but the subjects with insulin resistance may be relatively resistant to these effects of leptin ${ }^{32}$. Effects of leptin on glucose homeostasis and the 
ability of leptin to induce or improve insulin resistance suggests that a complex interplay exists between direct peripheral and centrally mediated effects of the hormone ${ }^{39}$. Interactions between leptin and insulin might have important implications in disruption of either insulin or leptin signaling associated with the metabolic syndrome ${ }^{40,41}$. Evidence from in vivo and in vitro studies supports the hypothesis that leptin and insulin signaling networks may overlap on several levels and play a crucial role in the regulation of glucose homeostasis. Leptin and insulin resistance occurring in the brain in pathological states such as diabetes are associated with insulin resistance in the periphery ${ }^{16,41}$.

As mentioned above we observed a significant correlation between leptin and hs-CRP in the deficient group. This result was the same as previous studies ${ }^{37,42,43}$. In line with our study, Shamsuzzaman et al. demonstrated that increased leptin is associated with increased CRP independently of gender, measures of adiposity, and other variables ${ }^{44}$. Similarly Goya et al. showed that increased leptin was independently associated with significant increases in inflammatory markers such as CRP ${ }^{45}$. Leptin can be described as a cytokine-like hormone with pleiotropic actions which can stimulate CRP production by the liver ${ }^{46}$. This association is the results of adipo-hepato-regulatory loop that involves stimulation of CRP expression by leptin and the feedback inhibition of leptin functions by $\mathrm{CRP}^{47}$. In chronic inflammatory states, CRP directly inhibits the binding of leptin to its receptors and blocks its ability to signal and leptin itself is able to directly stimulate CRP synthesis from the liver and from the vasculature $^{19,47}$. The interactions of leptin, HOMA-IR and hs-CRP in vitamin D deficient patients with type 2 diabetes were shown in Fig 3. No associations were found both between vitamin D and plasma glucose and between vitamin D and insulin resistance in our study. This result is consistent with Vilarrasa et al study ${ }^{48}$.

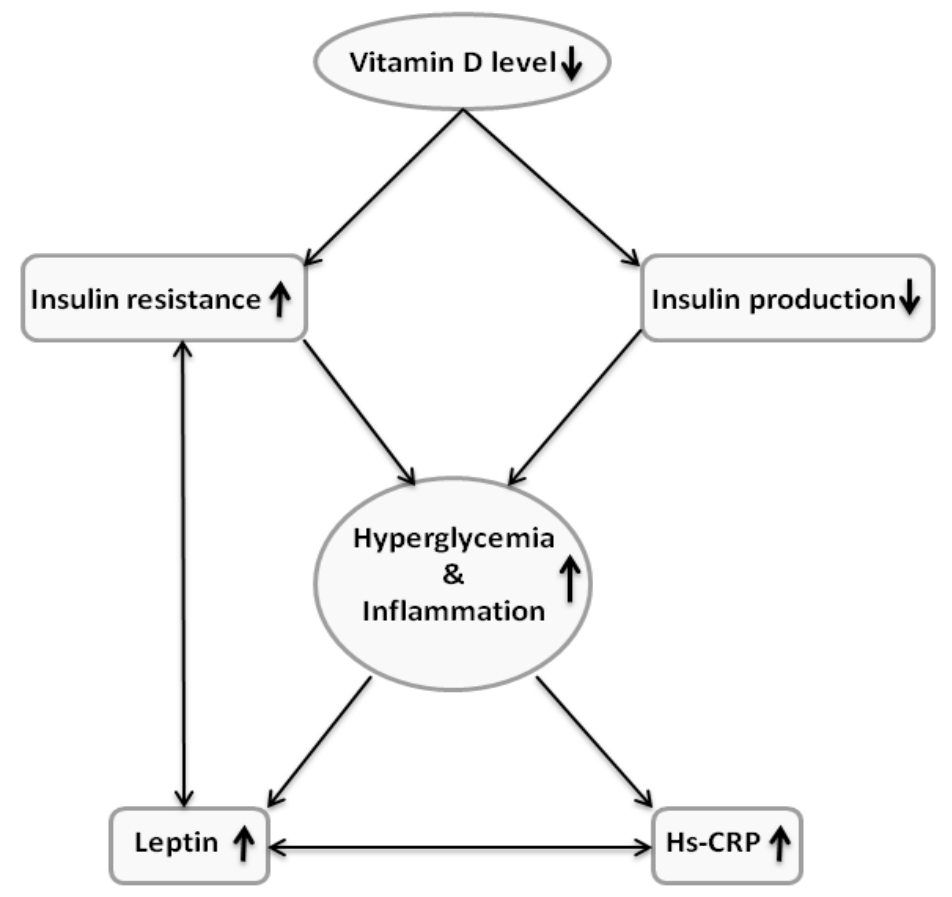

Fig 3: Theoretical framework for the interactions of leptin, HOMA-IR and hs-CRP in vitamin D deficient patients with type 2 diabetes. Vitamin D deficiency impairs insulin secretion and increases insulin resistance which results in aggravation of hyperglycemia (inflammatory state) and increasing the serum levels of hsCRP and leptin. There are bidirectional positive associations between leptin and hs-CRP and also between leptin and Insulin resistance. Leptin and Insulin directly regulate each other. 


\section{CONCLUSION}

Vitamin D deficient patients with diabetes had elevated FBS and PPG levels compared with insufficient ones. The findings presented herein have therapeutic implications. Diagnosis and treatment of vitamin D deficiency is easy and its correction may have a great therapeutic impact in diabetes. This study hypothesizes that, in patients with type 2 diabetes mellitus, normal levels of vitamin $\mathrm{D}$ in the blood may facilitate glucose control. The results also could possibly point the effect of vitamin D deficiency level on leptin associations with CRP and insulin resistance.

List of Abbreviations: HOMA-IR, Homeostatic Model Assessment for Insulin Resistance; hsCRP, High-sensitivity C-reactive Protein; CRP, C-reactive protein; FBS, Fasting Blood Sugar; BMI, Body mass index; PPG, Postprandial Glucose; CVD, Cardiovascular disease; GFR, Glomerular Filtration Rate; HDL-C, High-density lipoprotein cholesterol; LDL-C, Low-density lipoprotein cholesterol; CV, coefficient of variation; SD, standard deviation; SBP, systolic blood pressure; DBP, diastolic blood pressure; HbA1C, hemoglobin A1c.

Competing interest: There are no conflicts of interest to declare.

Author's Contributions: M Nakhjavani designed the study. A Esteghamati, S Rabizadeh and SS Salehi participated in the data collection, statistical analysis and drafting of manuscript. $\mathrm{H}$ Mirmiranpour participated in the laboratory evaluation, clinical assessment and study design. S Karimpour participated to provide oversight when the manuscript was being drafted. Marjan Mouodi provided advice regarding development of the protocol for the study. All authors read and approved the final manuscript.

Acknowledgments and Funding: Authors would like to appreciate the support and constructive comments of the methodologist(s) research development office, Vali-Asr Hospital, Tehran, Iran.

\section{REFERENCES}

1. Walsh JM, McGowan CA, Kilbane M, McKenna MJ, McAuliffe FM: The relationship between maternal and fetal vitamin D, insulin resistance, and fetal growth. Reproductive Sciences.2013; 20(5):536-541.

2. Oh J, Weng S, Felton SK, Bhandare S, Riek A, Butler B, Proctor BM, et al.: 1, $25(\mathrm{OH}) 2$ vitamin $\mathrm{D}$ inhibits foam cell formation and suppresses macrophage cholesterol uptake in patients with type 2 diabetes mellitus. Circulation.2009; 120(8):687-698.

3. Liu E, Meigs JB, Pittas AG, McKeown NM, Economos CD, Booth SL, Jacques PF: Plasma 25-hydroxyvitamin $d$ is associated with markers of the insulin resistant phenotype in nondiabetic adults. J Nutr.2009; 139(2):329-334.

4. Roth DE, Abrams SA, Aloia J, Bergeron G, Bourassa MW, Brown KH, Calvo MS, et al.: Global prevalence and disease burden of vitamin D deficiency: a roadmap for action in low- and middle-income countries. Annals of the New York Academy of Sciences.2018; 1430(1):44-79.

5. Palacios C, Gonzalez L: Is vitamin D deficiency a major global public health problem? The Journal of steroid biochemistry and molecular biology.2014; 144 Pt A:138-145.

6. Adorini L, Penna G: Control of autoimmune diseases by the vitamin D endocrine system. Nature clinical practice Rheumatology.2008; 4(8):404-412. 
7. Talmor Y, Golan E, Benchetrit S, Bernheim J, Klein O, Green J, Rashid G: Calcitriol blunts the deleterious impact of advanced glycation end products on endothelial cells. American Journal of Physiology-Renal Physiology.2008; 294(5):F1059-F1064.

8. Wolf M, Shah A, Gutierrez O, Ankers E, Monroy M, Tamez H, Steele D, et al.: Vitamin $\mathrm{D}$ levels and early mortality among incident hemodialysis patients. Kidney international.2007; 72(8):1004-1013.

9. Anderson JL, May HT, Horne BD, Bair TL, Hall NL, Carlquist JF, Lappe DL, et al.: Intermountain Heart Collaborative Study G. Relation of vitamin D deficiency to cardiovascular risk factors, disease status, and incident events in a general healthcare population. Am J Cardiol.2010; 106(7):963-968.

10. Mitri J, Muraru MD, Pittas AG: Vitamin D and type 2 diabetes: a systematic review. European journal of clinical nutrition.2011; 65(9):1005-1015.

11. Knekt P, Laaksonen M, Mattila C, Harkanen T, Marniemi J, Heliovaara M, Rissanen H, et al.: Serum vitamin $\mathrm{D}$ and subsequent occurrence of type 2 diabetes. Epidemiology.2008; 19(5):666-671.

12. Kabadi SM, Liu L, Auchincloss AH, Zakeri IF: Multivariate Path Analysis of Serum 25Hydroxyvitamin D Concentration, Inflammation, and Risk of Type 2 Diabetes Mellitus. Disease markers.2013; 35(3):187-193.

13. Alvarez JA, Ashraf A: Role of Vitamin D in Insulin Secretion and Insulin Sensitivity for Glucose Homeostasis. International Journal of Endocrinology.2010; 2010:351385.

14. Kabadi SM, Lee BK, Liu L: Joint Effects of Obesity and Vitamin D Insufficiency on Insulin Resistance and Type 2 Diabetes: Results from the NHANES 2001-2006. Diabetes Care.2012; 35(10):2048-2054.

15. Abbasi F, Okeke Q, Reaven GM: Evaluation of fasting plasma insulin concentration as an estimate of insulin action in nondiabetic individuals: comparison with the homeostasis model assessment of insulin resistance (HOMA-IR). Acta diabetologica.2014; 51(2):193197.

16. Moon H-S, Dalamaga M, Kim S-Y, Polyzos SA, Hamnvik O-P, Magkos F, Paruthi J, et al.: Leptin's Role in Lipodystrophic and Nonlipodystrophic Insulin-Resistant and Diabetic Individuals. Endocrine Reviews.2013; 34(3):377-412.

17. Menendez C, Lage M, Peino R, Baldelli R, Concheiro P, Dieguez C, Casanueva F: Retinoic acid and vitamin D (3) powerfully inhibit in vitro leptin secretion by human adipose tissue. Journal of endocrinology.2001; 170(2):425-431.

18. Giulietti A, Van Etten E, Overbergh L, Stoffels K, Bouillon R, Mathieu C: Monocytes from type 2 diabetic patients have a pro-inflammatory profile: 1, 25-Dihydroxyvitamin D3 works as anti-inflammatory. Diabetes Res Clin Pract.2007; 77(1):47-57.

19. Hribal ML, Fiorentino TV, Sesti G: Role of C reactive protein (CRP) in leptin resistance. Current pharmaceutical design.2014; 20(4):609.

20. Association AD: Standards of medical care in diabetes - 2015 abridged for primary care providers. Clinical diabetes: a publication of the American Diabetes Association.2015; 33(2):97.

21. Rahnavard Z, Eybpoosh S, Homami MR, Meybodi HA, Azemati B, Heshmat R, Larijani B: Vitamin D deficiency in healthy male population: Results of the Iranian multi-center osteoporosis study. Iranian journal of public health.2010; 39(3):45.

22. Taheri M, Baheiraei A, Foroushani AR, Modarres M: Resolving Vitamin D Deficiency in the Preconception Period among High-Risk Reproductive Women: A Randomized Controlled Trial. Iranian Red Crescent Medical Journal.2014; 16(1).

23. Holick MF, Chen TC: Vitamin D deficiency: a worldwide problem with health consequences. The American journal of clinical nutrition.2008; 87(4):1080S-1086S. 
24. Gonzalez E, Sachdeva A, Oliver D, Martin K: Vitamin D insufficiency and deficiency in chronic kidney disease. A single center observational study. American journal of nephrology.2004; 24(5):503.

25. National KF: K/DOQI clinical practice guidelines for bone metabolism and disease in chronic kidney disease. American journal of kidney diseases: the official journal of the National Kidney Foundation.2003; 42(4 Suppl 3):S1.

26. Association AD: Diagnosis and classification of diabetes mellitus. Diabetes care.2010; 33(Supplement 1):S62-S69.

27. Matthews D, Hosker J, Rudenski A, Naylor B, Treacher D, Turner R: Homeostasis model assessment: insulin resistance and $\beta$-cell function from fasting plasma glucose and insulin concentrations in man. Diabetologia.1985; 28(7):412-419.

28. Jazayeri M, Moradi Y, Rasti A, Nakhjavani M, Kamali M, Baradaran HR: Prevalence of vitamin D deficiency in healthy Iranian children: A systematic review and meta-analysis. Medical Journal of the Islamic Republic Of Iran.2018; 32(1):480-485.

29. Gradinaru D, Borsa C, Ionescu C, Margina D, Prada GI, Jansen E: Vitamin D status and oxidative stress markers in the elderly with impaired fasting glucose and type 2 diabetes mellitus. Aging clinical and experimental research.2012; 24(6):595-602.

30. Procopio M, Borretta G: Derangement of glucose metabolism in hyperparathyroidism. Journal of endocrinological investigation.2003; 26(11):1136-1142.

31. Zeitz U, Weber K, Soegiarto DW, Wolf E, Balling R, Erben RG: Impaired insulin secretory capacity in mice lacking a functional vitamin D receptor. FASEB journal : official publication of the Federation of American Societies for Experimental Biology.2003; 17(3):509-511.

32. Haffner S, Miettinen H, Mykkanen L, Karhapaa P, Rainwater D, Laakso M: Leptin concentrations and insulin sensitivity in normoglycemic men. International journal of obesity.1997; 21(5):393-399.

33. Fischer S, Hanefeld M, Haffner S, Fusch C, Schwanebeck U, Kohler C, et al.: Insulinresistant patients with type 2 diabetes mellitus have higher serum leptin levels independently of body fat mass. Acta diabetologica.2002; 39(3):105-110.

34. Zimmet P, Collins V, De Courten M, Hodge A, Collier GR, Dowse G, Alberti K, et al.: Is there a relationship between leptin and insulin sensitivity independent of obesity? A population-based study in the Indian Ocean nation of Mauritius. International Journal of Obesity \& Related Metabolic Disorders.1998; 22(2).

35. De Gusmao Correia ML, Haynes WG: Leptin, obesity and cardiovascular disease. Current opinion in nephrology and hypertension.2004; 13(2):215-223.

36. Denroche HC, Huynh FK, Kieffer TJ: The role of leptin in glucose homeostasis. Journal of diabetes investigation.2012; 3(2):115-129.

37. Chiu F-H, Chuang CH, Li W-C, Weng Y-M, Fann W-C, Lo H-Y, Sun C, et al.: The association of leptin and C-reactive protein with the cardiovascular risk factors and metabolic syndrome score in Taiwanese adults. Cardiovasc Diabetol.2012; 11:40.

38. Morton GJ, Schwartz MW: Leptin and the central nervous system control of glucose metabolism. Physiological reviews.2011; 91(2):389-411.

39. Ceddia RB, Koistinen HA, Zierath JR, Sweeney G: Analysis of paradoxical observations on the association between leptin and insulin resistance. The FASEB journal.2002; 16(10):1163-1176.

40. Knudson JD, Payne GA, Borbouse L, Tune JD: Leptin and mechanisms of endothelial dysfunction and cardiovascular disease. Current hypertension reports.2008; 10(6):434439. 
41. Paz-Filho G, Mastronardi C, Wong M-L, Licinio J: Leptin therapy, insulin sensitivity, and glucose homeostasis. Indian journal of endocrinology and metabolism.2012; 16(9):549.

42. Yanagawa T, Taniguchi A, Fukushima M, Nakai Y, Nagasaka S, Ohgushi M, Matsumoto $\mathrm{K}$, et al.: Leptin, triglycerides, and interleukin 6 are independently associated with Creactive protein in Japanese type 2 diabetic patients. Diabetes Res Clin Pract.2007; 75(1):2-6.

43. Viikari LA, Huupponen RK, Viikari JS, Marniemi J, Eklund C, Hurme M, Lehtimaki T,et al.: Relationship between leptin and C-reactive protein in young Finnish adults. The Journal of Clinical Endocrinology \& Metabolism.2007; 92(12):4753-4758.

44. Shamsuzzaman AS, Winnicki M, Wolk R, Svatikova A, Phillips BG, Davison DE, Berger PB, et al.: Independent association between plasma leptin and C-reactive protein in healthy humans. Circulation.2004; 109(18):2181-2185.

45. Wannamethee SG, Tchernova J, Whincup P, Lowe GD, Kelly A, Rumley A, et al.: Plasma leptin: associations with metabolic, inflammatory and haemostatic risk factors for cardiovascular disease. Atherosclerosis.2007; 191(2):418-426.

46. Lago F, Dieguez C, Gomez-Reino J, Gualillo O: Adipokines as emerging mediators of immune response and inflammation. Nature Clinical Practice Rheumatology.2007; 3(12):716-724.

47. Chen K, Li F, Li J, Cai H, Strom S, Bisello A, Kelley DE, et al.: Induction of leptin resistance through direct interaction of C-reactive protein with leptin. Nature medicine.2006; 12(4):425-432.

48. Vilarrasa N, Vendrell J, Maravall J, Elio I, Solano E, San Jose P, García I, et al.: Is plasma $25(\mathrm{OH})$ D related to adipokines, inflammatory cytokines and insulin resistance in both a healthy and morbidly obese population? Endocrine.2010; 38(2):235-242. 